Article

\title{
Saphenous Vein Graft between Brachial Artery and Cephalic Vein in Antebrachial Arteriovenous Anastomosis - Simulation of the Procedure
}

\author{
Lilija Banceviča ${ }^{1}$, Dzintra Kažoka ${ }^{2}$, Aleksandrs Maḷcevss ${ }^{3}$, Māra Pilmane ${ }^{4}$ \\ ${ }^{1}$ Faculty of Medicine, Rīga Stradiņš University, Riga, Latvia; lilijabancevica@gmail.com \\ 2 Department of Morphology, Institute of Anatomy and Anthropology, Rīga Stradin̄š University, Riga, Latvia; \\ Dzintra.Kazoka@rsu.lv \\ ${ }^{3}$ Latvian Transplant Centre, Pauls Stradiņš Clinical University Hospital, Riga, Latvia; \\ Aleksandrs.Malcevs@rsu.lv \\ ${ }^{4}$ Department of Morphology, Institute of Anatomy and Anthropology, Rīga Stradiṇš University, Riga, Latvia; \\ Mara.Pilmane@rsu.lv
}

\begin{abstract}
Patients with chronic renal failure and vascular diseases require the vascular access for hemodialysis procedure to be performed with the most possible comfort for the patient. Native vein graft has a longer-lasting term in the patients' limb, lower risk of graft infection and lower price. Native vein graft is constructed from the great saphenous vein, if the diameter of the vessel is smaller than the diameters of vessels (brachial artery, cephalic vein) it is connected to in the cubital fossa region due to the risk of graft folding, that might occur, if the graft diameter is bigger than the diameter of one or both vessels, on which anastomosis is made. The most important sizes, that were taken before graft placement, are the length of the forearm compartment, the distance between the brachial artery and cephalic vein in the cubital fossa region, distance from an expected incision in the brachial artery to the middle of the forearm compartment, the distance between incision in cephalic vein to the middle of the forearm compartment, length of the great saphenous vein (the graft) and diameters of blood vessels, used in the procedure. Finally, the right position of the graft should be determined for the successful outcome of anastomosis creating procedure.
\end{abstract}

Keywords: arteriovenous graft, hemodialysis, vascular access, anastomosis

\section{Introduction}

The arteriovenous graft is a type of vascular access. For the graft insertion most, preferred places are arm or forearm with the most often chosen blood vessels - the brachial artery and cephalic or basilic vein, or lower limb, where the femoral artery and femoral vein are chosen for arteriovenous connection [24]. Left or right extremity is chosen, depending on patient comfort (right-handed, lefthanded), anamnesis (vascular diseases, emboly, previous surgeries). The graft is recommended for nephrology department patients with chronic renal failure, which is one of the most prevalent worldwide public health problems in the field of nephrology, that affects functions of the kidney. Some of the curing methods for chronic renal failure are kidney transplantation, hemodialysis or peritoneal dialysis [27]. While the patient is waiting for the kidney donor, he/she needs to be undergoing a hemodialysis procedure. The arteriovenous graft is a frequent procedure in the hemodialysis unit due to easier access to blood vessels, which lets the medical staff perform hemodialysis faster and improve patient comfort. The procedure for inserting the graft into the patient's extremity, as well as the graft maintenance, requires the integrity of vascular surgery, nephrology, infectiology, radiology professionals and dialysis department specialists for successful treatment and care of the patient. 
In Pauls Stradiņš Clinical University Hospital, the Latvian Transplant Centre in Riga, Latvia, as well as in other hospitals in the world, prosthetic graft is a method of vascular access for dialysis, however, many problems, associated with prosthetic graft may occur [27]. The patient's native vein is more preferred than prosthesis due to the lower risk of infection and sepsis. Arteriovenous graft lasts 5-10 years longer than synthetic graft, which is important for patients, who are waiting in queue for the kidney donor $[14,19]$. In some patients' cases, native vein graft is a better option, due to the lower expenditure. According to information from the transplantology and hemodialysis center specialists in Pauls Stradiňš Clinical University Hospital, prices of synthetic vascular grafts in Latvia vary from 600 Eur and more per vessel (the price is provided as an information from "Baltijas Dializzes Serviss" ("The Baltic Centre of Dialysis"), 7 March 2018), but native vein does not have any material costs for the patients, except the surgery procedure, which is usually state paid, if the patient has health insurance, however the diagnosis and surgery affect patient's mental and physical health.

The arteriovenous graft is used to provide the patient with initial vascular access for hemodialysis. Saphenous vein graft is an approach for the arteriovenous anastomosis when one end of a saphenous vein is inserted into the artery and another end into the vein to make the connection between blood vessels. Saphenous vein graft is often used in coronary bypass surgery [3]. To minimize the risk of complications, the great saphenous vein was chosen for the procedure over the synthetic graft.

This study aims were to establish the length of the great saphenous vein for creating antebrachial anastomosis and to insert the saphenous vein into the anterior compartment of the forearm to make the graft between the brachial artery and cephalic vein.

\section{Materials and Methods}

\subsection{Preparation}

Materials and corpse, that were used in the procedure, were provided by the Laboratory of Anatomy and Anthropology of Department of Morphology at the Institute of Anatomy and Anthropology, Rīga Stradiňš University. In the procedure, the right arm and left leg of the corpse were used. The saphenous vein graft model for the hemodialysis procedure was made in the Complete Anatomy 2020 app for the better visualization and imagination of an actual arteriovenous graft.

The cubital fossa and forearm region of the right arm of the corpse were chosen for the anastomosis creating procedure due to the easier vascular access of the brachial artery and cephalic vein (Figure 1. Error! Reference source not found.). Regular forearm graft placement was chosen with arteriovenous graft location from the cubital fossa to the middle of the forearm compartment. The middle of the forearm compartment was established by measuring the distance from the middle of the cubital fossa region to the flexor retinaculum of the hand and dividing the distance by two. The great saphenous vein from the anterior compartment of the left leg was chosen for the procedure (Figure 1. a). During the study, several anatomy books, atlases (Sobotta, Complete Anatomy 2020 3D anatomy platform), medical studies from PubMed.gov (National Center for Biotechnology Information, U.S. National Library of Medicine), Medicina (1996-2020, MDPI (Basel, Switzerland) ResearchGate (20082020 ResearchGate GmbH) databases, "Vascular Access: Principles and Practice" book, "Journal of Vascular Surgery" were used. Publications, used in our study, were observed and read from November, 2019 to August, 2020. 
Key inclusion and exclusion criteria for publications included the following: studies describing the use of the great saphenous vein in arteriovenous anastomosis creation in the forearm compartment, as well as the risk of infection of the graft and native vein use in other surgical manipulations, such as coronary bypass creation for the purposes of surgical education and training were analyzed in this article. There were included studies from 2000 to present day. Only publications in the English language were used. In the present study publication data from 17 countries (Australia, Belgium, Canada, France, Germany, Greece, India, Israel, Italy, Korea, Latvia, Lebanon, Muscat, Singapore, Taiwan, United Kingdom, United States of America) was included. There were excluded articles about people less than age 18, animal studies, reviews, editorials and studies describing dissection techniques for anatomy teaching without performing any procedure and clinical/functional outcome. Stenosis, vascular abnormalities and emboly on the body side, where procedure was planned to be performed, were excluded.

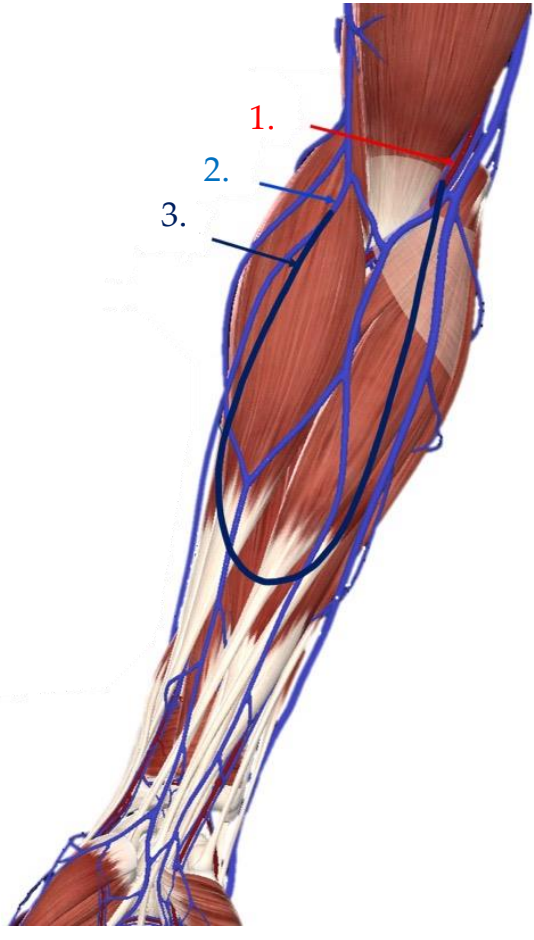

$a$

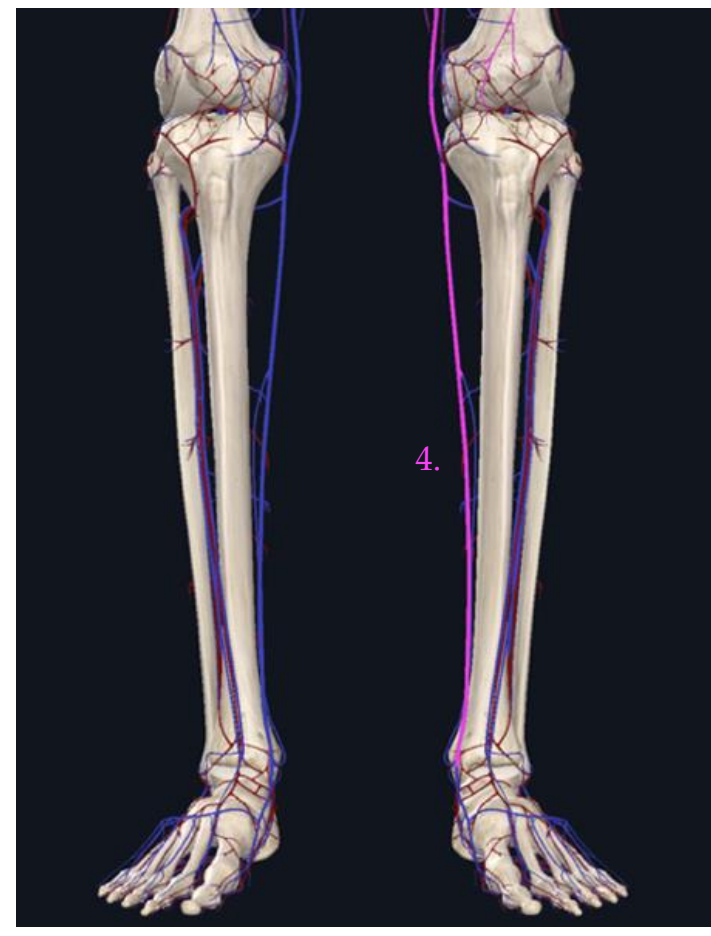

$a$

Figure 1. Modeling of the saphenous vein graft in Complete Anatomy 2020 app. (a) Cubital fossa and forearm compartment of the right arm: 1 - brachial artery, 2 - cephalic vein, 3 - great saphenous vein; (b) lower part of the left leg: 4 - great saphenous vein. Adapted from Complete Anatomy 2020 app (Copyright (C) 2020 3D4Medical. All rights reserved.), modified by Banceviča et al., 2020.

\subsection{Diameters and Thrombosis Risk Reduction}

The brachial artery, cephalic vein and great saphenous vein diameters were measured by using Vernier calliper to make sure, that the diameter of the great saphenous vein is not bigger than the diameters of blood vessels the graft would be connected to. 
After the blood vessel diameters were measured and the possibility of the saphenous vein use in vascular anastomosis creation between the brachial artery and the cephalic vein was established, skin and adipose tissue were dissected from the brachial artery and cephalic vein in the cubital fossa region by using a surgical scalpel, surgical and anatomical tweezers. Median and cutaneous nerves with branches were moved aside to free the brachial artery and cephalic vein. Connective tissue was removed from blood vessels. Skin and fat tissue were removed from the great saphenous vein in the anterior compartment of the leg. Connective tissue was removed from the great saphenous vein. Moving nerves, as well as closely lying to the working surface blood vessels allows lowering the risk of damaging closely located anatomical structures of the body.

\subsection{Measurements}

Locations for incisions in the brachial artery and cephalic vein were chosen and marked. Incisions were marked as close to the middle of the cubital fossa region, as possible for the ability to flex and extend the arm after the graft placement, so movements of the forearm could be performed, as before graft insertion. The following measurements were done for establishing sufficient length of the great saphenous vein for the graft creation.

\subsection{Distances}

1 - the distance between incision location in the brachial artery to incision location in the cephalic vein was measured; 2 - the distance between incision location in the brachial artery to the middle of the forearm compartment was measured; 3 - the distance between incision location in cephalic vein to the middle of the forearm compartment was measured and summed to establish the length of the saphenous vein graft. The standard error of the Vernier calliper of $\pm 0.05 \mathrm{~mm}$ was used for reinsurance of the measurement and size sufficiency in the anastomosis creating procedure.

\subsection{Anastomosis Creation}

The great saphenous vein was measured in the anterior compartment of the leg, ligation and dissection of great saphenous vein branches were done. Ligation and dissection of the great saphenous vein from the leg were done by using surgical forceps and Surgipro 7-0 sutures [7]. Diameters of the great saphenous vein graft ends were measured to establish incision sizes in the brachial artery and cephalic vein. Saphenous vein graft ends sized incisions were made in the brachial artery and cephalic vein. One saphenous vein graft end was connected to the brachial artery and the second end was connected to the cephalic vein by using Surgipro 7-0 sutures and straight stainless steel hemostat. The vascular anastomosis was done. The angle of the graft folding was established.

\section{Results}

\subsection{Diameters of Blood Vessels}

The great saphenous vein diameter was $2.12 \mathrm{~mm}$, diameter of the brachial artery was $4.48 \mathrm{~mm}$, diameter of the cephalic vein was $2.46 \mathrm{~mm}$, which allowed the procedure to be performed with insurance of graft not being folded and not causing any pathologies and circulatory disorders with consecutive thrombosis and graft abruption.

\subsection{Sizes and Distances}


The size of the anterior compartment of the forearm was $254.7 \mathrm{~mm}$, the size of the great saphenous vein in the anterior compartment of the leg was $322.75 \mathrm{~mm}$. The distance from the incision in the cephalic vein to the graft folding place was $107.3 \mathrm{~mm}$ and the distance from the brachial artery to the graft folding place was $129.9 \mathrm{~mm}$. The length of the great saphenous vein for antebrachial arteriovenous anastomosis creation between the brachial artery and cephalic vein should be 304.81 $\mathrm{mm}$, if the distance between brachial artery and cephalic vein in the cubital fossa and forearm region is $18.01 \mathrm{~mm}$. The distance from the saphenous graft connection to the brachial artery and cephalic vein region to the middle of the forearm compartment was $128.40 \mathrm{~mm}$. The distance from an incision in the cephalic vein to the graft folding place was $107.3 \mathrm{~mm}$ and the distance from an incision in the brachial artery to the graft folding place was $129.9 \mathrm{~mm}$ (Table 1 . Sizes of the measured parts. The angle of the graft folding was $80^{\circ}$.

\begin{tabular}{|llc|}
\hline Nr. & \multicolumn{1}{|c}{ Measured part } & $\begin{array}{c}\text { Length / diameter / } \\
\text { distance, } \\
\text { mm }\end{array}$ \\
\hline 1. Diameter of great saphenous vein & $2.12 \pm 0.05$ \\
2. Diameter of brachial artery & $4.48 \pm 0.05$ \\
3. Diameter of cephalic vein & $2.46 \pm 0.05$ \\
4. Length of anterior compartment of the forearm & $254.70 \pm 0.05$ \\
5. Length of great saphenous vein & $322.75 \pm 0.05$ \\
6. Distance from brachial artery to cephalic vein & $18.01 \pm 0.05$ \\
7. Distance from incision in cephalic vein to the graft folding place & $107.30 \pm 0.05$ \\
8. Distance from incision in brachial artery to the graft folding place & $129.90 \pm 0.05$ \\
\hline
\end{tabular}

Table 1. Sizes of the measured parts.

\section{Discussion}

In this study, we observed the possibility of great saphenous vein use in arteriovenous anastomosis in the forearm compartment between the brachial artery and cephalic vein. Sizes of the anterior compartment of the forearm, distance from brachial artery to a cephalic vein in cubital fossa region, distance from an incision in the brachial artery to the graft folding place, distance from an incision in cephalic vein to the graft folding place, length of the great saphenous vein in the anterior compartment of the leg below the knee, diameter of the brachial artery, diameter of the cephalic vein and diameter of the great saphenous vein are crucial for the successful outcome of the procedure. We have detected sufficient sizes for the possible use of the patient's vein to make the anastomosis between the brachial artery and cephalic vein in the 
cubital fossa region of the forearm and used the native patients' graft as a connective material, instead of prosthetic graft material, which is commonly used in similar procedures in nephrology unit.

According to our study, it is possible to use the native vein of the patient, as a graft in the hemodialysis unit in cases of chronic renal failure [16]. The research provides new insight into the use of native vein of the patient in nephrology, hemodialysis and vascular surgery fields [15].

According to many epidemiological types of research [11, 25], in graft placement methods synthetic material is used in vascular anastomosis creation in patients with chronic kidney failure. The method of prosthetic vascular graft insertion has major extracavitary infection outcomes due to claudication and tissue loss $[2,13]$. The most used material in prosthetic grafts is polytetrafluoroethylene (PTFE) vascular grafts, known for the elasticity and greater compliance, than grafts, used before, and Dacron grafts. The risk of infection in polyurethane graft use in graft placement surgery is $33-37.5 \%$. The risk of Dacron graft infection is $29 \%[9,23]$. The infection in polyurethane grafts is more common than Dacron graft infection [4]. The great saphenous vein is used as a graft in coronary bypass surgery [5], the use of prosthetic grafts is less common in coronary bypass procedure [20]. The risk of saphenous vein graft failure in a coronary bypass surgery is $20-25 \%$, which shows, that native vein graft material allows the procedure to be more successful, than in the case of prosthesis use [21]. Arteriovenous fistulas have a lower incidence of infection of 0.2 to 0.4 per 1000 fistula days, compared to the grafts, which proves the lesser risk of infection of native body's material use in vascular access [18].

In the forearm compartment, graft diameter should be small due to the diameters of the brachial artery and cephalic vein, which are relatively small to other blood vessels in the human body and the blood flow rate in these vessels is relatively lower [11]. The importance of diameter measurement of the graft is connected with the possibility of graft folding, when it is being connected to other blood vessels, to the brachial artery and cephalic vein. If the diameter of prosthetic or biological graft is bigger than the blood vessel diameter, used in the vascular anastomosis, there is a possibility of graft ends folding, which could lead to the abnormal blood flow with a result of emboly [26]. To reduce the risk of thrombosis caused by neointimal hyperplasia and decreased blood flow, measurement of diameters is crucial before starting the actual procedure [6]. It can be done, by using ultrasound and angiography as a non-invasive method of diagnostics. If the diameter of the great saphenous vein is bigger than the diameter of blood vessels, that are planned to be connected to form arteriovenous anastomosis, it is recommended to use either a prosthetic graft or the biological graft, that is taken from the own patient's extremities, for example, the radial artery.

Several studies have evaluated the risk of such complication occurrence as bacterial and viral infection and graft abruption after and during prosthetic graft insertion and connection procedure [8, 17]. A disadvantage of the prosthetic graft connection method is the lack of autologous material (graft) for the bypass creation, which leads to overstimulated blood flow or opposite the insufficient blood flow due to thrombus formation on the prosthesis wall and increased risk of emboly. The main reason of bypass failure, that occurs due to the nonautologous graft use in connection procedure, is horizontal or vertical graft folding. Graft folding elevates the risk of graft infection and emboly [11, 22, 28]. Our results demonstrate that native vein can be used in arteriovenous anastomosis creating procedure and lower risks of occurrence 
of infectious disease in future rehabilitation of the patient, who outwent the graft placement surgery and is outgoing the hemodialysis.

The risk of blood clot formation in the lower extremity after great saphenous vein extraction is minimal due to the leg blood circulation system. Veins, that could continue to function are short saphenous vein, which is anastomosing with great saphenous vein, posterior tibial veins, fibular veins, anterior tibial veins. The oxygen-deficient blood would flow up the large circle of blood to the right atrium of the heart starting from medial and lateral plantar veins, anastomosing with posterior tibial veins, from a lateral marginal vein, anastomosing with small saphenous vein and dorsal and plantar metatarsal and digital veins, anastomosing with marginal veins of the foot.

The great saphenous vein graft allows to elongate of the graft lasting in the patient's limb, which is important for patients, who require kidney transplantation and are waiting for the donor. Our study provides information for future researches and clinical use of native patients vein in transplantology and vascular surgery departments of hospitals.

\subsection{Limitations of the Study}

This study has several limitations. First, we cannot exclude, that in some patients' body the native vein graft will be rejected or vasodilation will occur faster, than using the prosthetic graft, which will depend on individual reaction to the new structure in the forearm compartment, hypoxia, nutrition, different growth factor (platelet-derived growth factor, vascular endothelial growth factor) activity, the presence or lack of everyday physical activity, changes in body temperature, hypotension et cetera [9, 10,12]. A second limitation, we had no possibility to perform the procedure clinically on the patient due to the limited access to the hospital and lack of the researches, in which the great saphenous vein was used as arteriovenous anastomosis connective structure, except cardiovascular surgery researches with the saphenous vein in coronary bypass surgery [1].

\subsection{Strengths of the Study}

To our knowledge, this is the first study, that investigates the use of great saphenous vein as a graft in forearm arteriovenous anastomosis. The novelty of the study allows transplantology and vascular surgery units to start using native patients' vein instead of synthetic material, prosthesis and provide patient the longer-lasting effect of the graft with a much lesser risk of graft failure due to the vascular muscle cell proliferation and inflammation, which depends on such factors, as a platelet-derived growth factor, vasoconstrictive substances, angiotensin, proinflammatory molecules and thromboxane, in vein-to-artery and vein-to-vein anastomosis, taking into account both vein connection ends [10]. The study extends the possibility of native vessel use in transplantology, vascular surgery departments and lowers the risk of different complications, that usually occur in procedures of prosthetic graft integration as a foreign structure in patients' bodies.

\subsection{Future Research}

Further research is needed to establish the saphenous vein graft function in alive patients' bodies. Future studies will include the simulation of blood flow in the forearm compartment of 
the corpse by using sodium chloride physiological solution and saphenous graft placement in patients' forearm compartment for establishing the graft function with the real blood flow.

\section{Conclusions}

To sum up, our results provide evidence, that the great saphenous vein can be used as a vascular graft in the anastomosis creation in the anterior compartment of the forearm. There is a risk of graft folding with following graft rejection by native patients' tissues, if the graft is placed too high due to the flexion and extension of the forearm and due to the larger diameter, than diameters of blood vessels, which are being connected in the graft placement procedure. The right position and size of the graft have to be chosen for the successful outcome of the procedure.

Supplementary Materials: Supplementary Materials can be found at AppStore, Microsoft, GooglePlay "Complete Anatomy 2020", the information about graft costs can be found in the protocol of procurement commission Nr. PSKUS 2018/1.

Author Contributions: Conceptualization, L.B., D.K. and A.M.; Methodology, L.B., D.K. and A.M.; Validation, L.B., D.K. and A.M.; Formal Analysis, L.B., D.K. and A.M.; Investigation, L.B., D.K. and A.M.; Resources, L.B., D.K., A.M. and M.P.; Data Curation, L.B., D.K., A.M. and M.P.; Writing - Original Draft Preparation, L.B. D.K. and A. M.; Writing - Review \& Editing, L.B., D.K., A.M. and M.P.; Visualization, L.B.; Supervision, D.K., A.M. and M.P.; Project Administration, D.K., A.M. and M.P. All authors have read and agreed to the published version of the manuscript.

Funding: This research received no external funding.

Acknowledgments: The Authors thank the staff of Laboratory of Anatomy at the Department of Morphology and specialists of transplantology in Pauls Stradiňš Clinical University Hospital.

Conflicts of Interest: The authors declare no conflict of interest.

\section{References}

1. Al-Sabti, H.A.; Al Kindi, A.; Al-Rasadi, K.; Banerjee, Y.; Al-Hashmi, K.; Al-Hinai, A. Saphenous vein graft vs. radial artery graft searching for the best second coronary artery bypass graft. Journal of the Saudi Heart Association. 2013;25(4):247-254. DOI:10.1016/j.jsha.2013.06.001

2. Almasri, J.; Alsawas, M.; Mainou, M.; Mustafa, R.A.; Wang, Z.; Woo, K.; Cull, D.L.; Murad, M.H. Outcomes of vascular access for hemodialysis: A systematic review and meta-analysis. Journal. of Vascular Surgery. 2016;64(1):236-243. DOI:10.1016/j.jvs.2016.01.053

3. Altshuler, P.; Welle, N.J. Saphenous Vein Grafts. In: StatPearls. Treasure Island (FL): StatPearls Publishing; 2020.

4. Anderson, J.E.; Chang, A.S.; Anstadt, M.P. Polytetrafluoroethylene hemoaccess site infections. ASAIO Journal. 2000;46(6):S18-S21. DOI:10.1097/00002480-200011000-00032

5. Bachar, B.J.; Manna, B. Coronary Artery Bypass Graft. In: StatPearls. Treasure Island (FL): StatPearls Publishing; 2020.

6. Bagher, P.; Segal, S.S. Regulation of blood flow in the microcirculation: role of conducted vasodilation. Acta Physiologica. 2011;202(3):271-284. DOI:10.1111/j.1748-1716.2010.02244.x

7. Ball, C.G.; Feliciano, D.V. A simple and rapid vascular anastomosis for emergency surgery: a technical case report. World Journal of Emergency Surgery. 2009;4:30. DOI:10.1186/1749-7922-4-30

8. Benrashid, E.; Youngwirth, L.M.; Mureebe, L.; Lawson, J.H. Operative and perioperative management of infected arteriovenous grafts. Journal of Vascular Access. 2017;18(1):13-21. DOI:10.5301/jva.5000613 
9. Desai, M.; Hamilton G. Graft Materials Past and Future. In: Fitridge, R.; Thompson, M., eds. Mechanisms of Vascular Disease: A Reference Book for Vascular Specialists. Adelaide (AU): University of Adelaide Press; 2011.

10. Duffy A.; Bouchier-Hayes D; Harmey J. Vascular Endothelial Growth Factor (VEGF) and Its Role in Non-Endothelial Cells: Autocrine Signalling by VEGF. In: Madame Curie Bioscience Database [Internet]. Austin (TX): Landes Bioscience. 2011, DOI:10.1007/978-1-4419-9148-5_13.

11. Etkin, Y.; Rao, A.; Jackson, B.M.; Fishbein, J.S.; Shyta, K.; Baig, H., et al. Infections of prosthetic grafts and patches used for infrainguinal arterial reconstructions. Annals of Vascular Surgery. 2018; DOI: 10.1016/j.avsg.2018.09.015.

12. Folkmane, I.; Tzivian, L.; Folkmane, E.; Valdmane, E.; Kuzema, V.; Petersons, A. Predictors of Hyperuricemia after Kidney Transplantation: Association with Graft Function. Medicina (Kaunas). 2020;56(3):95. DOI:10.3390/medicina56030095

13. Gharamti, A.; Kanafani, Z.A. Vascular Graft Infections: An update. Infectious Disease Clinics of North America. 2018;32(4):789-809. DOI:10.1016/j.idc.2018.06.003

14. Hung, Y.N.; Ko, P.J.; Ng, Y.Y.; Wu, S.C. The longevity of arteriovenous graft for hemodialysis patients--externally supported or nonsupported. Clinical Journal of the American Society of Nephrology. 2010;5(6):1029-1035. DOI:10.2215/CJN.08181109

15. Jindal, K.; Chan, C.T.; Deziel, C.; Hirsch, D.; Soroka, S.D.; Tonelli, M.; Culleton, B.F. Hemodialysis clinical practice guidelines for the Canadian Society of Nephrology. Journal of American Society of Nephrology. 2006;17(3 Suppl 1):S1-S27. DOI:10.1681/ASN.2005121372

16. Kilic, A; Arnaoutakis, D.J.; Reifsnyder, T.; Black, J.H. 3rd.; Christopher, J.A.; Bruce, A.P.; Ying, W.L. Management of infected vascular grafts. Vascular Medicine. 2016;21(1):53-60. DOI:10.1177/1358863X15612574

17. Legout, L.; Sarraz-Bournet, B.; D'Elia, P.V.; Devos, P.; Pasquet, A.; Caillaux, M.; Wallet, F.; Yazdanpanah, Y.; Senneville, E.; Haulon, S.; Leroy, O. Characteristics and prognosis in patients with prosthetic vascular graft infection: a prospective observational cohort study. Clinical Microbiology and Infection. 2012, pp. 352-358

18. MacRae, J.M.; Dipchand, C.; Oliver, M.; Moist, L.; Yilmaz, S.; Lok, C.; Leung, K.; Clark, E.; Hiremath, S.; Kappel, J.; Kiaii, M.; Lusckombe, R.; Miller, L.M. Arteriovenous Access: Infection, Neuropathy, and Other Complications. Canadian Journal of Kidney Health and Disease. 2016, 3:2054358116669127. DOI:10.1177/2054358116669127

19. Maya, I.D.; Weatherspoon, J.; Young, C.J.; Barker, J.; Allon, M. Increased risk of infection associated with polyurethane dialysis grafts. Seminars in Dialysis. 2007;20(6):616-620. DOI:10.1111/j.1525-139X.2007.00372.x

20. McKavanagh, P.; Yanagawa, B.; Zawadowski, G.; Cheema, A. Management and Prevention of Saphenous Vein Graft Failure: A Review. Cardiology and Therapy. 2017;6(2):203-223. DOI:10.1007/s40119-017-0094-6

21. Melly, L.; Torregrossa, G.; Lee, T.; Jansens, J.L.; Puskas, J.D. Fifty years of coronary artery bypass grafting. Journal of Thoracic Disease. 2018;10(3):1960-1967. DOI:10.21037/jtd.2018.02.43

22. Nassar, G.M.; Ayus, J.C. Clotted arteriovenous grafts: a silent source of infection. Seminars in Dialysis. 2000;13(1):1-3. DOI:10.1046/j.1525-139x.2000.00006.x

23. Park, K.M.; Kim, Y.W.; Yang, S.S.; Kim, D.I. Comparisons between prosthetic vascular graft and saphenous vein graft in femoro-popliteal bypass. Annals of Surgical Treatment and Research. 2014;87(1):35-40. DOI:10.4174/astr.2014.87.1.35 
24. Pei Ho, J. Practical Guide to Surgical and Endovascular Hemodialysis Access Management, World Scientific Publishing Co. Pte. Ltd. 2015; pp 23-28

25. Samuel, E.W. Vascular Access: Principles and Practice, 2009; pp 31-120

26. Santoro, D.; Benedetto, F.; Mondello, P.; Pipito, N.; Barillà, D.; Spinelli, F.; Ricciardi, C.A.; Cernaro, V.; Buemi, M. Vascular access for hemodialysis: Current perspectives. International Journal of Nephrology and Renovascular Disease. 2014, 7. 281-294. DOI:10.2147/IJNRD.S46643.

27. Vadakedath, S.; Kandi, V. Dialysis: A Review of the Mechanisms Underlying Complications in the Management of Chronic Renal Failure. The Cureus Journal of Medicine. 2017;9(8):e1603. DOI:10.7759/cureus.1603

28. Zetrenne, E.; McIntosh, B.C.; McRae, M.H.; Gusberg, R.; Evans, G.R.; Narayan, D. Prosthetic vascular graft infection: a multi-center review of surgical management. Yale Journal of Biology and Medicine. 2007, 80(3):113-121 